\title{
Study on the high frequency of large fan speed control system on coal
}

\author{
mine \\ Xinling Zhao \\ Linyi University,Linyi Shandong,276000,China \\ zhaoxinling@lytu.edu.cn
}

\section{Keywords:fan;VFD;PLC}

Abstract:Fan coal mine as one of the main equipment, electrical power, with $24 \mathrm{~h}$ operation every day, there is a serious power consumption.Aiming at the problems of cyclone machine adjustment method, the use of $10 \mathrm{kV}$ high-voltage inverter realize remote control, and have achieved good energy saving effect.

\section{Introduction}

As a fan of coal mine production of the necessary equipment, it must operate $24 \mathrm{~h}$ every day to ensure the smooth flow of coal mine ventilation, to prevent the harmful gas such as gas accumulation (highlight)and other accidents. However, with the continuous extension of tunneling and mining face, the required air volume will increase, and fans will also be used to increase the power. And temperature changes with the seasons, the required amount of wind coal mine also need to be adjusted accordingly. But coal mine air volume fan design is based on the selection of production, so the fan power is much greater than its actual shaft power, which has a serious energy consumption, resulting in a great waste of energy.

Coal Fan equipments have a large power, and the motor is running at full speed.The directing start of motor is bound to cause a greater impact on the grid, which will directly affect the life of the fan, and affect the normal operation of other electrical equipment of the power grid, so ventilation machine start should be soft start mode. Frequency control can be the best choice to solve the problem of fan start, but also to solve the problem of fan energy consumption.

\section{System Design}

(1)System Design Principles.Frequency control of motor speed can be achieved within a wide range of AC motors, which will be detected at any load conditions during operation and adjust the power output of the motor automatically. Then the motor will be always running at its best in the entire,which has a high efficiency of speed range and obvious energy saving effect.It is not only in line with the national policy to promote energy conservation, but better cost savings for enterprises to create a huge economic benefits. The solution for VFD to reduce motor speed is to change the power supply frequency. It is from $10 \mathrm{kV}$ or $6 \mathrm{kV}$ power line, the phase-shifting transformers and high-voltage inverter, directly or $6 \mathrm{kV} 10 \mathrm{kV}$ output to the motor without step-up / step-down inverter-type process.

(2)Design plan.Motor Type and power: In view of the rotating Fan motor working environment, stress characteristics and control, explosion-proof motor is used in the reconstruction project, and the motor adopts SKF bearing insulation. To cope with variable frequency drive way, the motor 
winding insulation class do the appropriate consideration. As the motor is located inside the duct, combined because of harmonics, insulation levels and other factors have an impact on the cooling of the motor ,so that the motor uses a forced air cooling method, namely through the installation of explosion-proof motor rear cooling fan to solve this problem. Gravity and motor bearing thin oil lubrication, the lubricant is rotated by a natural suction motor bearings, bearing lubrication to achieve the purpose of lubricating device is mounted on the external fan, as well as to protect the safety of operation of the motor. The motor bearings and windings embedded vibration PT100 RTD, bearing seat mounted horizontally, vertically vibration sensor for monitoring the fan, and the motor power is $1800 \mathrm{~kW}$.

Electronically controlled systems: electronic control system main equipment uses HIVERT series drives, which with a "one to one" drive mode under normal condition. The drives have been increase the power frequency circuits. By switching links, the links appear in the inverter circuit failure as a backup, shown in Fig1.

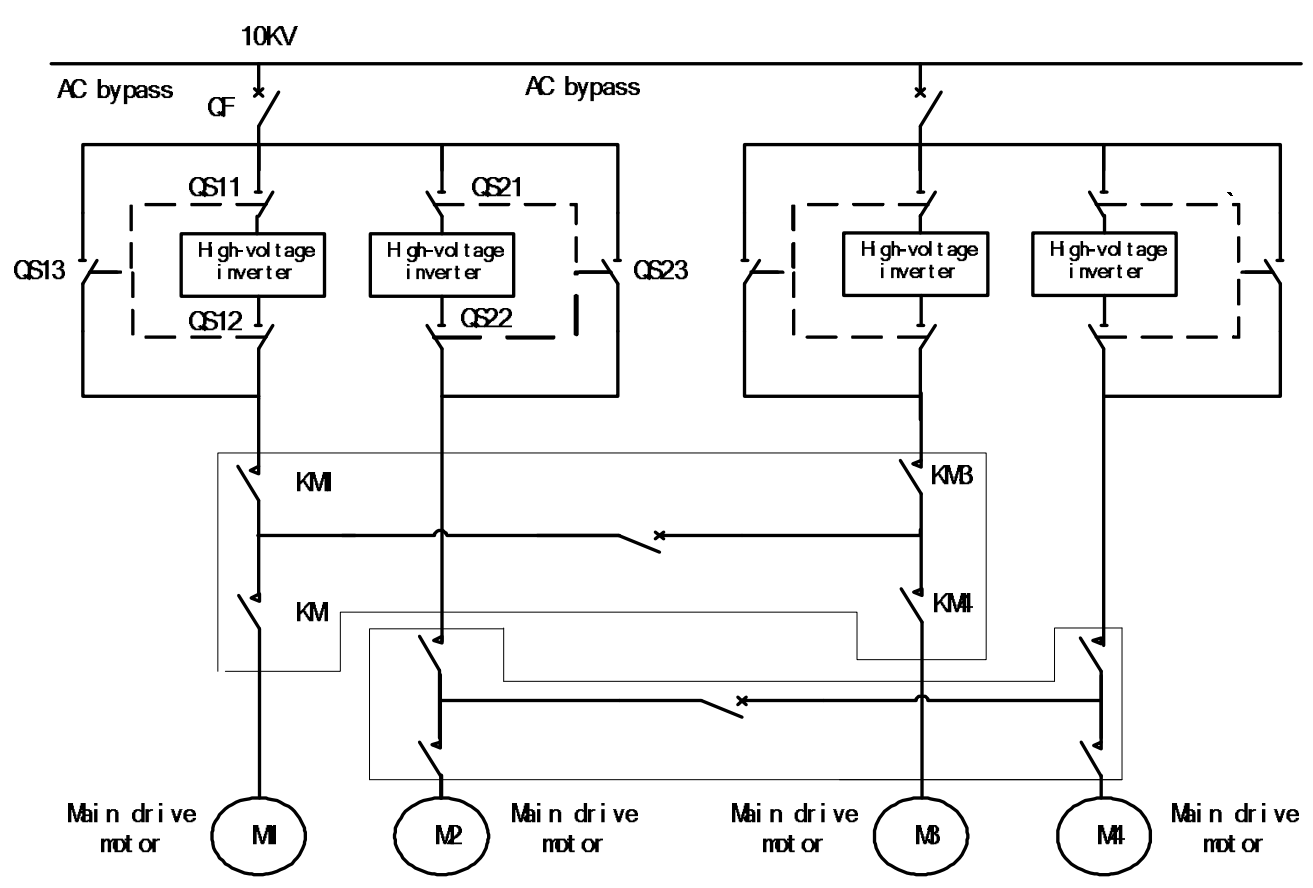

Fig.1 control loop

Due to the special nature of the ventilation system, fans are used in work with a preparation of design. System mainly consists of high-voltage power supply cabinet, high-voltage inverter cabinet, central control console and related high voltage switchgear components. High voltage power supply cabinet, namely high-voltage inverter power supply cabinet, which was in addition to the conventional protection, it also have remote tripping interface essential to insure that when the inverter output trip signal, the switchgear can cut off the power supply of the inverter.

During routine work, the current is supplied through the inverter output cabinet to a high-voltage inverter output of the two motors Tornado aircraft, so that the two motors rotate at the same speed reverse, providing the impetus for a continuous supply of wind turbines; and bypass cabinet inverter system is needed repaired or failure backup system frequency, then for each fan, frequency inverter system has become the system's backup system, completely beyond the conventional system design requirements with a preparation. When not using frequency bypass, meaning that when there is no frequency bypass cabinet, frequency counters can also cancel the output, and frequency output is directly connected to two motors. 
In the control, the control portion of the body as a whole system with redundant PLC system configuration, and the control section includes: a conventional control system, the system switches control the fan and motor status real-time detection, power distribution system status detection. Control system operating data within the system all devices timed recording, real-time data using the run-time curve are described, truly "quantitative system status" while standby power control system uses real-time hot backup work to ensure that "the Lord, standby "system is always in a state of being monitored. In this work, the user can fault the electronic control system to do real-time location, and through the fan curve analysis, users can specific risks predictable system, shown in Fig.2.

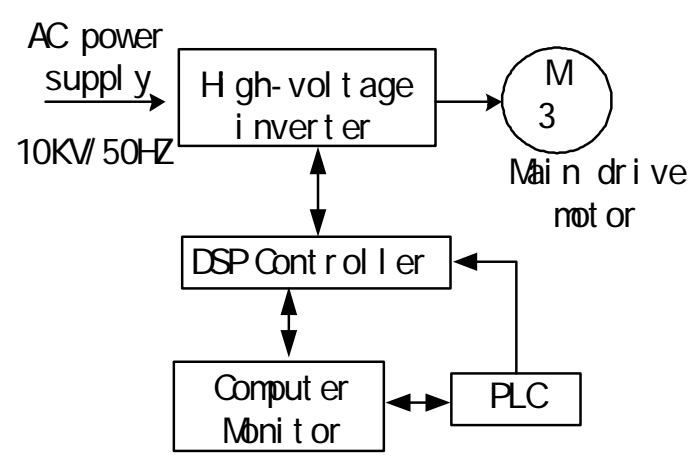

Fig.2 inverter control chart

(3)System Works. (1) Normal mode.First, the angle of the blade to run fans and standby fan are adjusted to the maximum position, which identified the need to run wind turbines, closed inverter power supply cabinet, and then start operation at the operating table, delay after $3-5$ s automatically starts slowly Frequency device, and in this process, they can always adjust the amount of air the fan running, the air supply from the operating table of a given frequency potentiometer determines when the frequency increases, the air volume increases; when the frequency is reduced, reducing the amount of wind. In operation, the speed indicator changes as the frequency of the synchronization changes until the system to meet the air supply requirements.

When the fan is running fails or needs an overhaul, the system console can be automatically or manually by the realization of a wind turbine to run another wind turbine operation. Therefore, these two wind turbines to achieve a mutual backup, to ensure system security and stability.

(2) Anti-wind mode.In the process of mine ventilation test or maintenance, operation need to mine in the wind with no downtime, simply by operating the stage anti-wind knob, then run the fan will slowly stop, and then reverse slowly start and run before work on the anti-wind speed, to ensure the maintenance of mine under special circumstances and requirements.

\section{System Features}

(1) The system uses two sets of a drag control mode (one inverter drives a fan of a motor), even if an inverter fails, another set of the system can still variable-frequency operation, then the entire system can still running its best.

(2) Frequency conversion system can run on the fan to realize continuous stepless speed regulation. By adjusting the output frequency of the inverter to change the fan speed to achieve the purpose of adjusting the amount of wind. That is to meet the technical requirements, but also to maximize energy savings. 
(3) For the device with high voltage, low current, in order to ensure the overall system to match the output, the inverter can reach $10 / 6 \mathrm{kV}$, directly connected to the $10 / 6 \mathrm{kV}$ motor overall efficiency is further improved. Internal equipment without any boost links.

(4) Harmonic grid can meet the requirements of GBT14549 motor,and common motor can be used directly without any special requirements.

(5)The drive itself overload, overcurrent, overvoltage, undervoltage, such as improving the automatic protection.

(6) In order to meet the load can get good speed characteristics of any speed in the process, reducing equipment wear and tear, you can limit the run phase inverter 4 , and the direct energy feedback grid.

(7)Console real-time monitoring of all ventilation systems of electrical equipment, make the right decisions for the attendant to provide strong technical assurance, and conventional fault automatically processed.

(8) Taking into account the on-site space limitations, phase-shifting transformers, high-voltage inverter and control devices are used in parallel set of cabinets installed to reduce the volume. Frequency converter for air cooling way to reduce the amount of maintenance

\section{Conclusion}

Through practical operation of the inverter, the comprehensive performance of the fan has a big improvement, comprehensive benefits to achieve the maximization. Due to low frequency fan starting current is small, reduces the starting torque, so as to protect the motor, prolong the service life of the motor; fan noise during normal operation, significantly reduced, improving the working environment for staff on duty. When the fan fails the display text prompts the drive and automatically store fault information, so convenient troubleshooting and shorten the maintenance and overhaul time; at the same time between the frequency and the frequency are associated with sensitive between 1 and 2 blower fan lock relationship maximizes equipment, personnel security; The inverter frequency can be adjusted easily at runtime, to meet the actual air pressure and air flow needs to change the original air volume control mode, reducing the work intensity, improving work efficiency, expanding the use of space fans to avoid surge voltage generation. High-voltage devices reduce the failure rate and prolong the working life of the fan, to ensure the normal operation of the fan. While frequency control devices can automatically switch to an alternate frequency devices or automatically switch to standby motor. Through six months of follow-up observations, it is easy to control the system, power saving, and achieved good economic results.

\section{References}

[1] Yi Peng.Technology principle and application of high voltage high power inverter [M ].Beijing: People's Posts and Telecommunications Press, 2012.

[2] Guo Yaohua, Ye Shuang. Application of inverter in motor test platform [J]. Electric Machines \& Control Application,2011(7).

[3] Zhang Hao, continued Ming Jin, Yang Mei. High power AC adjust speed system [M].Beijing: China Machine Press, 2010.

[4] Han Anrong, Man Yongkui, Wu Chengdong. Universal frequency converter and its application [M].Beijing: China Machine Press,2012. 